\title{
Quebec Seeks Solutions: An Economic Development Agency's Role in Local Open Innovation
}

\author{
Alexandra Berger Masson
}

\author{
"The best way to have a good idea is to have a lot of ideas." \\ Linus Pauling (1901-1994) \\ Two-time Nobel Laureate (Physics and Chemistry)
}

\begin{abstract}
This article offers an economic-development perspective on a new method for local companies to find innovative solutions to their most challenging business problems: local open innovation. Quebec International, the economic development agency for the Quebec City area, contributed to the development of the Seeking Solutions approach to local open innovation, which included the hosting of problem-solving conferences with local research centres, economic development actors, and companies. Looking back on our experiences and outcomes since 2010, this article shows how the development and introduction of this new approach to local open innovation has changed the rules of the game in the region.
\end{abstract}

\section{Introduction}

Innovation and collaboration between local actors are seen as key ingredients for successful economic development. Thus, Quebec International (QI; quebec international.ca), the economic development agency for the Quebec City area, was keen to contribute to the development of a new approach to bringing local partners together to solve complex business problems: the Seeking Solutions approach to local open innovation. The opportunity arose in 2010 when Quebec International was approached by IDTEQ (Regroupement pour l'innovation et le développement technologique de Québec; idteq.ca), a group of research centres that sought new methods of business development. The approach took the form of a conference where real company problems are discussed and where the regional economic actors can interact to bring solutions. The first "Quebec Seeks Solutions" event took place in December 2010, in parallel with a symposium of the International Society for Professional Innovation Management (ISPIM; ispim.org). Here, we look back on this first event and subsequent similar events to show how local open innovation can support economic development.
Although it is common for regional economic development agencies to work with research centres and companies, these interactions are not usually simultaneous, and encouraging these two parties to work together was not traditionally part of most agencies' day-to-day activities. Nonetheless, with Quebec being home to the second-highest number of researchers per Canada, Quebec International decided that it should take advantage of these regional competencies and help in developing a new approach to collaboration. The result the Seeking Solutions approach - brought new ways for the industrial research centres in Quebec City to collaborate, and it provided a new method for local companies to find innovative solutions to their most challenging business problems. It also changed the game in terms of redefining the role that an economic development agency can play in stimulating collaboration and innovation among regional actors.

In this article, we describe how an economic development agency can act as a catalyst to combine regional strengths and allow companies to be more efficient with the help of external innovation from nearby research centres. We first provide background informa- 


\title{
QSS: An Economic Development Agency's Role in Local Open Innovation
}

\author{
Alexandra Berger Masson
}

tion to set the scene for the development of the approach. Next, we show how Quebec International has helped mobilize the region and position local open innovation as "a new reflex". Finally, we present some key results and show how the model has even inspired other regions in the world to similarly engage local actors and stimulate open innovation.

\section{Context}

As an integrated economic development agency, Quebec International promotes the Quebec City metropolitan region's competitive business environment in order to attract foreign investment and qualified workers. However, Quebec International does much more than promoting and attracting investment. In fulfilling its mission of fostering company growth, supporting key sectors, and attracting talent, it offers companies a full and varied slate of services. As with other economic development agencies, Quebec International also supports marketing and export-related initiatives; high-tech innovation; and entrepreneurship. Quebec International focuses on the development and growth of the following key sectors of excellence: i) information and communications technologies (ICT) and electronics; ii) life sciences; iii) food processing, iv) insurance and financial services; and v) green and smart building. With this mission, the agency develops tight and privileged links with local companies, especially those from the key sectors. Quebec International's role includes introducing new methods of working to organizations throughout the region, thereby promoting the diffusion of the best international practices.

Considering these premises, Quebec International was immediately interested in participating in an initiative to stimulate innovation in companies. In partnership with the five research centres of IDTEQ (Box 1), SOVAR (sovar.com; an organization devoted to the development and commercialization of new technologies derived from university research and from partnering research centres), and the Quebec Metro High Tech Park (parc techno.com; in which all of these organizations are situated), Quebec International started to work on the Quebec Seeks Solutions conference that had been initiated after a two-day workshop on the topic of open innovation. Quebec Seeks Solutions is a problem-solving conference where companies submit challenging problems that they are not able to solve themselves. Following a broadcast of the problems, problem solvers are invited to collaborate with the problem owners during a oneday working session. For details of the Quebec Seeks Solutions events and the Seeking Solutions approach to local open innovation, see Christophe Deutsch's (2013; timreview.ca/article/664) article in this issue of the TIM Review.

Because of its mandate to help companies to grow, Quebec International decided to place the Quebec Seeks Solutions event at the centre of its strategic plan to increase the innovation in the Quebec region. In fact, such an event helps to compensate for the lack of link between the needs for innovation (i.e., the companies) and the actual offer that can create high value (i.e., the local $R \& D$ centres, universities, others). The event also helps the whole local ecosystem of innovation to acquire the ability of using open innovation to create value more quickly. Relative to Europe and the United States, we perceive delayed progress with open innovation in Quebec and Canada; it is our hope that a focus on local open innovation can help us close this gap.

\section{Mobilization}

Quebec International regularly organizes large conferences at regional, national, and international scales; however, a Quebec Seeks Solutions event is unlike any other conference and therefore needed a new framework. The challenges for Quebec International were directly related to one of its main activities: mobilizing the local innovation system in order to increase value creation.

\section{Mobilizing companies to submit a problem}

The first mobilization challenge was to encourage local companies to submit problems. In effect, Quebec International, with the help of its partners and relays, had to sell the Quebec Seeks Solutions model to the compan-

Box 1. IDTEQ research centres

- CRIQ: the industrial research centre for the Province of Quebec

- COREM: a consortium of applied research organizations for the processing and transformation of mineral substances

- FP Innovations: a forest research centre

- INO: the National Institute for Optics Research

- IRDA: the Research and Development Institute for the Agri-Environment 


\title{
QSS: An Economic Development Agency's Role in Local Open Innovation
}

\author{
Alexandra Berger Masson
}

ies. The major problem was that we had no idea of what the event would look like. The premises used to sell the concept were mainly based on the fact that Quebec Seeks Solution was a large experimentation field where the companies could test open innovation in a real-life scenario.

We could not ask companies to simply make a "leap of faith"; rather, we convinced them to submit problems by presenting the key assumptions behind the concept. The first assumption was that open innovation is used more and more in the United States and in Europe by large enterprises, with excellent success stories and return-on-investment stories (e.g., Forrester Consulting; 2010; tinyurl.com/alp9ujl). We asked: can a Canadian company that wants to innovate really not even try open innovation?

The second assumption related to the complexity of the problems. Due to its knowledge of local companies, Quebec International knew that some important, complex problems were lying unsolved for far too long and were limiting the potential expansion of some enterprises. There was therefore more to gain than to lose in exposing these problems. The worst that could happen was that the problem would stay unsolved. Quebec International challenged some managers to participate based on this assumption. When a company has lost months or years trying to solve a complex problem, the chance that it could finally solve it became attractive the company just had to confess its inability to solve the problem itself. And so, Quebec International was able to convince several companies that only risk was the status quo. We explained that Quebec Seeks Solutions is not only about finding new solutions to old problems; the event also provides companies with an opportunity to validate or invalidate existing solution ideas, to refine and better understand a problem, and to find "the real problem" behind a problem.

Furthermore, Quebec International had extensively surveyed local innovation resources and found that many local companies were underutilizing the potential of researchers from applied R\&D centres such as IDTEQ or from universities. The main reason for this underutilization related to perception and communication. Offering efficient researchers the opportunity to work for an entire day on a real industrial problem will bring a double benefit. For the researcher, it is a good way to orient their future research on industry problems. For company's employee; it could be a good way to see how researchers could quickly bring about potential solutions. The potential expected benefit of solving com- plex, long-term problems would therefore be larger than only solving a short-term problem, and it held promise for fostering a culture of openness in the region.

However, even with all these excellent augments in favour of participating, companies were still reluctant to share their problems. In particular, large companies were afraid to expose their information, because the market is global and a competitor can emerge from anywhere; strategic information is highly sensitive. Controlling the message was a major concern, and thus, the final obstacle in mobilizing companies to submit problems related to intellectual property. Thanks to Quebec International's network, the law firm Fasken Martineau (fasken.com) agreed to answer questions and guide the participating companies with respect to intellectual property issues during the event. Intellectual property in the context of collaboration is a specialty of Fasken and more specifically of one of its partners: JeanNicolas Delage (tinyurl.com/agdbl9n).

Small and medium-sized enterprises were also concerned about losing time and money. Since we had no success stories to share, we proposed flexible ways of engagement for smaller companies and we lowered the barrier to entry by making the costs of participation low for the first event.

Thanks to the efforts of Quebec International and its partners - particularly IDTEQ - nine pioneer companies proposed ten problems to the first event in December 2010. Even with concrete results from the first event, the call for problems for the second event in 2012 remained a time-consuming task. It was still a question of convincing people they had more to gain by participating. However, eight companies submitted nine problems in May 2012. For the third event in fall 2013, Quebec International expects that this task will become easier because of the concrete results from the two first events and because of the cultural change is slowly taking place in the region.

\section{Mobilizing problem solvers to participate in the event} Once the problems are submitted, the work to make the event a success is still not finished. One has to ensure that the right people will participate in the event to maximize the likelihood that novel and effective solutions to the problems will be proposed. For the Quebec Seeks Solutions events, we drew upon the entire economic development ecosystem to help recruit potential solvers from within and beyond their organizations. This ecosystem includes all of the public and private organizations that support innovation and growth, such 


\title{
QSS: An Economic Development Agency's Role in Local Open Innovation
}

\author{
Alexandra Berger Masson
}

as the chambers of commerce, sectorial associations, and government services. Of course, the fact that IDTEQ was a major partner ensured the participation of at least 30 researchers, and their participation encouraged other partners to participate as well.

IDTEQ also designed the research component of the event, which included assigning researcher "ambassadors" to the companies whose problems were selected. The role of the ambassadors was to delimitate and properly describe a company's problem so that the problem solvers would have a clear and well-defined starting point. As they gained in-depth knowledge of the problems, the ambassadors were able to identify expertise that may be required to solve the problems. Thus, we were able to make targeted calls to specific university departments and companies to invite them to participate as problem solvers, based on their relevant expertise.

Public partners for research and innovation financing were also contacted to advise companies on funding options for later implementation of any solutions that arose during the event. These organizations provided advice on tax credits, innovation audits, and innovation marketing support, as well as direct access to the public innovation-financing programs provided by the Natural Sciences and Engineering Research Council of Canada (NSERC; nserc-crsng.gc.ca) and the National Research Council of Canada's Industrial Research Assistance Program (NRC-IRAP; nrc-cnrc.gc.ca/eng/irap/).

In December 2010, 170 people participated in the first Quebec Seeks Solutions event, and in May 2012, 160 people participated in the second event. Quebec International and its partners are very proud of these two events, not only because companies so many companies and problem solvers decided to try the process, but because real results were achieved, as will be described in the next section. These events directly align with the mandate of Quebec International as an economic development agency. We have therefore already announced the 2013 event and are convinced that an annual event of this type will continue to generate high value for the region. Mobilizing the problem owners and problem solvers required a substantial effort from Quebec International and its partners, but we feel that the value of results demonstrate that these efforts were worthwhile.

\section{Numbers and Facts}

Real results for the participating companies

To evaluate the impact of the Quebec Seeks Solutions events on the participating companies, Quebec International monitors their progress every six months during the first year after the event and then every year thereafter. The partial results in the beginning of 2013 reveal that 6 out of 17 companies are still working on a solution proposed during the Quebec Seeks Solutions process. Considering the problems these companies submitted were complex and long-standing, these results are encouraging. Four of these companies entered into contracts with research groups and most of them invested in research and development (internally) to apply pieces of the solution they received at the event. Within the first cohort of 2010, 7 out of 9 companies reported one or two direct benefits from their participation.

One of the companies from the first event is shortly going to market with a new product that directly resulted from a solution proposed during the 2010 event. Another company from the 2012 edition is realizing a huge economy of time - and consequently money - by applying a new process originating from the 2012 event; this solution may transform the company's business model with an investment of a few hundred dollars. Another company, through its interactions with problem solvers, learned about a regional industry that it was previously unaware of; it found a new supplier, its products now will be $100 \%$ made in Quebec, and the market value of its products will increase.

\section{Indirect impacts}

In 2011, Quebec International organized two smaller Seeking Solutions events in the Geospatial sector (one of the key sectors of the region). We took the opportunity to apply what we perceived as a "winning approach" in dedicated sectorial clusters in order to renew the way that an economic development organization can support these clusters. The reception by the industrial partners has been very positive and the initiative gave birth to two major regional projects. As a catalyzer in the area, Quebec International can now play its role of gathering the different community members together to solve problems even more effectively with the Seeking Solutions approach.

Another major impact of the approach resulted from the unique, high-value networking that occurs through collaboration during the events. The event allowed people from different organizations and different fields to communicate in a way that is far more profitable than the typical networking model of "brief chats and business-card exchanges". Two companies from the first event have discovered how they are complementary and how they could work together on common pro- 


\title{
QSS: An Economic Development Agency's Role in Local Open Innovation
}

\author{
Alexandra Berger Masson
}

jects. Two research centres proposed a common service offer to a company and won a contract they could not have won on their own.

For Quebec International, simply achieving collaboration between companies is an impact all on its own, and is a positive indicator for the future development of the region. The rarefaction of highly educated people (due to an aging population) and the pressure from developing countries with more dynamic demographies will increase the need for new approaches to collaboration. Thanks to its experience with Quebec Seeks Solutions, Quebec International is ready as an economic development entity to support its region for these future challenges.

However, the indirect impacts of the events extent beyond the province of Quebec; the approach responds to a need in many other regions or cities. For example, the Maintenance Value Park initiative in the Netherlands described in this issue of the TIM Review by Oscar Smulders (2013; timreview.ca/article/666) - has been inspired by what has been developed in the Quebec region. Therefore, Quebec International also contributes to the creation of an international community around local open innovation. In fact, Quebec International invited Oscar Smulders to participate in the second Quebec Seeks Solutions event and this relationship works toward the goal of including working sessions in future events to exchange knowledge and good practices of local open innovation. This side effect also helps the region to been seen internationally as very dynamic and innovative.

Finally, some of the key players behind the two Quebec Seeks Solutions events created a company - En Mode Solutions (enmodesolutions.com) - in order to offer the Seeking Solutions approach to other regions, to industrial clusters, to conferences, or even to large companies. The creation of this startup is another important result and demonstrates that the investment of Quebec International into the Quebec Seeks Solutions events has created great value.

\section{Conclusion}

Quebec Seeks Solutions events create a meeting point between companies who need support to solve some of their most complex problems and potential solvers, such as other companies, research centres, and uni- versities, which may have already faced the same type of problem or can bring relevant expertise and novel solutions. Quebec International, as the regional economic development agency, had to be part of this initiative because it corresponds directly to its mandate of helping companies grow and increasing value creation in the region.

Due to its central role of support for the different economic development actors within the entrepreneurial ecosystem of the Quebec City area, Quebec International has been able to contribute to the development of this initiative and help make it a success. The main contributions of Quebec International were to research financing, to find partners to address the intellectual-property questions, to mobilize the innovation ecosystem to encourage companies submit problems, and to help recruit problem solvers. Furthermore, Quebec International contributes by monitoring and documenting the results obtained from the different events to validate that the perceived value is proven over time. Of course, Quebec International was not alone in this initiative, and IDTEQ played a central role in the success of Quebec Seeks Solutions.

In terms of cultural change within the region, Quebec International has played a key role in promoting innovation in companies through this model of local open innovation. Research centres and companies can now count on using Quebec Seeks Solutions events to solve complex problems together in the Quebec region. These collaborations between research centres and companies will make Quebec the most efficient region in the world for solving complex problems. Quebec International is very proud to be associated with this new approach to innovation: local open innovation.

Quebec International is already working on the next Quebec Seeks Solution event, which will be held on November 6, 2013, and on other Seeking Solutions events in the key sectors of activities of the Quebec region, in collaboration with the newly formed company: En Mode Solutions. Quebec International will therefore continue to innovate in the best practices of economic development.

\section{Recommended Reading}

- "Local Open Innovation: The 'Seek Solutions' Approach" (tinyurl.com/a846dl9) 


\title{
QSS: An Economic Development Agency's Role in Local Open Innovation
} Alexandra Berger Masson

\begin{abstract}
About the Author
Alexandra Berger Masson is Director of Corporate Affairs at Quebec International, which includes responsibility for innovation projects. She has worked for Quebec International since 2008 and lived the second Quebec Seeks Solution experience as the Project Manager. In previous economic development roles with Quebec International she, managed projects in applied technology and technology entrepreneurship. She has a PhD in Philosophy and in Cognitive Sciences and has worked on the creation of an expressive language for artificial agents in the artificial intelligence domain.
\end{abstract}

Citation: Berger Masson, A. 2013. Quebec Seeks Solutions:

An Economic Development Agency's Role in Local Open

(cc) BY

Innovation. Technology Innovation Management Review.

March 2013: 27-32.

Keywords: economic development, local open innovation,

Quebec Seeks Solutions, private research and development,

open innovation, collaboration 